UCRL-JC-120907

CONF $-9505238--4$

\title{
Safety Aspects with Regard to Plutonium Vitrificaton Techniques
}

\author{
Leonard W. Gray and Tehmau Kan \\ RECEIVED \\ OCT 061995 \\ OSTI
}

This paper was prepared for presentation at the NATO International Scientific Exchange Programmes

Advanced Research Workshop

St. Petersburg, Russia

May 14-17, 1995

\section{May 11, 1995}
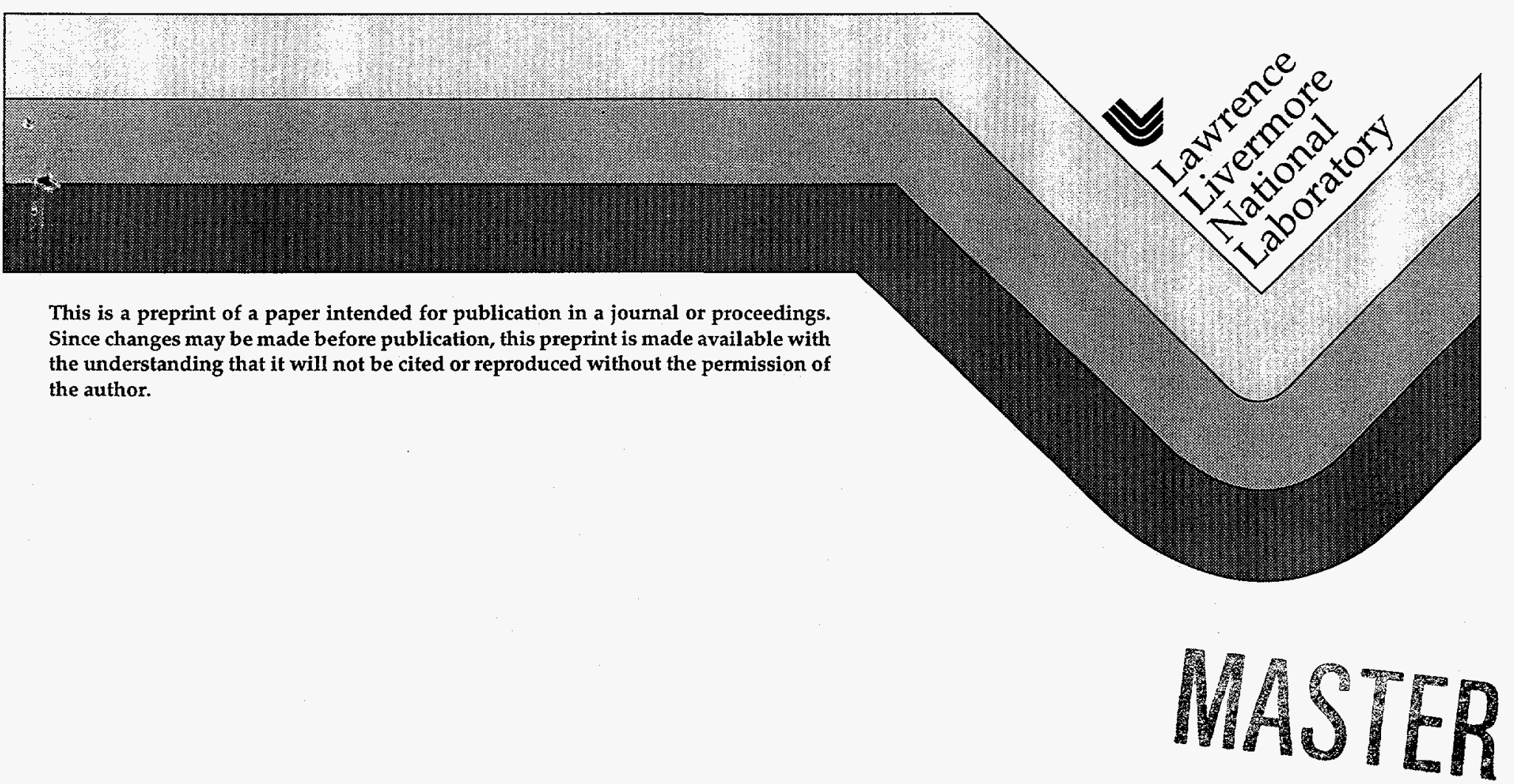


\section{DISCLAMMER}

This document was prepared as an account of work sponsored by an agency of the United States Government. Neither the United States Government, nor the University of California, nor any of theiremployees makes any warranty, express or implied, or assumes any legal liability or responsibility for the accuracy, completeness, or usefulness of any information, apparatus, product, or process disclosed, or represents that its use would not infringe privately owned rights. Reference herein to any specific commercial products, process, or service by trade name, trademark, manufacturer, or otherwise, does not necessarily constitute or imply its endorsement, recommendation, or favoring by the United States Government or the University of California. The views and opinions of authors expressed herein do not necessarily state or reflect those of the United States Government or the University of California, and shall not be used for advertising or product endorsement purposes.

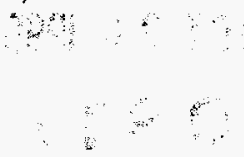




\section{DISCLAIMER}

Portions of this document may be illegible in electronic image products. Images are produced from the best available original document. 


\title{
SAFETY ASPECTS WITH REGARD TO PLUTONIUM VITRIFICATION TECHNIQUES
}

\author{
LEONARD W. GRAY AND TEHMAU KAN \\ Lawrence Livermore National Laboratory \\ P.O. Box 808, L-592, Livermore, CA 94551 USA
}

Substantial inventories of excess plutonium are expected to result from dismantling U.S. and Russian nuclear weapons. Disposition of this material should be a high priority in both countries. Various disposition options are under consideration. One option is to vitrify the plutonium with the addition of ${ }^{137} \mathrm{Cs}$ or high-level waste to act as a deterrent to proliferation. The primary safety problem associated with vitrification of plutonium is to avoid criticality in form fabrication and in the final repository over geologic time. Recovery should be as difficult (costly) as the recovery of plutonium from spent fuel.

\section{INTRODUCTION}

In the aftermath of the Cold War, significant quantities of enriched uranium and weapons-grade plutonium have become surplus to national defense needs in both the United States and Russia. These excess stockpiles pose a danger to national and international security, not only in the potential proliferation of nuclear weapons but in the potential for environmental, safety, and health consequences if these fissile materials (FMs) are not properly managed.

If agreed reductions are implemented, perhaps 100 metric tonnes of $\mathrm{Pu}$ will no longer be needed for military purposes by the Nuclear Weapons States. Continued implementation of arms reduction agreements will result in further dismantling of weapons and increasing stockpiles of surplus weapons-usable materials.

With the transformation of the Soviet Union into the Commonwealth of Independent States and the economic and social challenges faced by those newly formed states, there is a serious risk of nuclear proliferation from the resulting growing stockpiles. Nuclear weapons or fissile materials could fall into the hands of terrorists or non-nuclear nations through theft or diversion of FMs. The U.S. 
National Academy of Sciences report (NAS) (Ref. 1) on the management and disposition of excess weapons plutonium characterized this as a "clear and present danger." This nuclear danger is, in many ways, more diffuse, harder to manage, and more dangerous than the nuclear tensions of the Cold War era.

To aid in selecting long-term management options for weapons surplus $\mathrm{Pu}$, the U.S. Department of Energy (DOE) has undertaken a multifaceted study to select options for storage and disposition in keeping with the national policy that excess $\mathrm{Pu}$ must be subjected to the highest standards of safety, security, and international accountability. Disposition is defined as a process of use or disposal of materials that results in the remaining material being converted to a form substantially and inherently more proliferation-resistant than the original form. Disposition options must take into account technical, nonproliferation, environmental, and economic considerations. As a part of the overall disposition program, Russia and other nations with relevant interests and experience will be invited to participate in the overall disposition study.

The disposition process (Fig. 1) can be divided into three distinct but overlapping phases-dismantling, intermediate storage, and long-term disposition. Dismantling of U.S. and Former Soviet Union (FSU) weapons and storage of resulting fissile materials (FM) are already under way. Conversion of residue materials and long-term disposition of all FM will take far longer to accomplish.

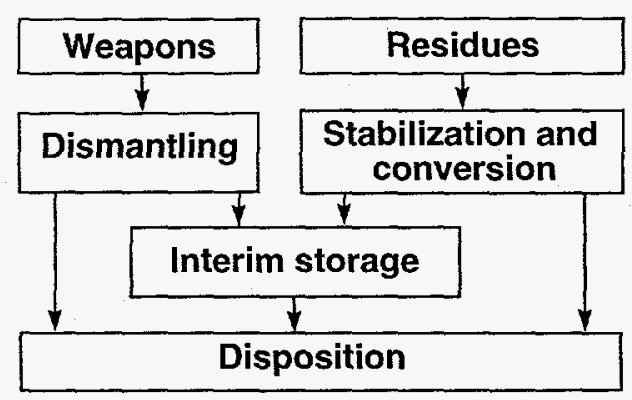

Figure 1. Steps in control and disposition of surplus fissile materials.

One disposition alternative considered for $\mathrm{Pu}$ is immobilization. In support of DOE's Materials Disposition (MD) Project Office's Programmatic Environmental Impact Statement (PEIS) for Disposition of Pu, Lawrence Livermore National Laboratory was selected as Lead Laboratory to study and recommend methods for transforming $\mathrm{Pu}$ into long-term immobilized forms meeting environmental, safety, and security objectives; to provide appropriate input to other Disposition Tasks Teams so as to assess the technical feasibility of immobilization as a long-term 
disposition option; and describe infrastructures required to dispose of Pu. Support laboratories include Westinghouse Savannah River Technology Center (South Carolina), Argonne National Laboratory (Illinois), Oak Ridge National Laboratory (Tennessee), Pacific Northwest Laboratory (Idaho), Rocky Flats Environmental Technology Site (Colorado), and Westinghouse Hanford Company (Washington).

\subsection{IMMOBILIZATION OPTIONS}

Immobilization would embed $\mathrm{Pu}$, alone or mixed with radioactive fission products, in a tailored ceramic, borosilicate glass, or other suitable material to produce a suitable disposal form. To be economically viable, the $\mathrm{Pu}$ concentration must be in the range 0.4 to $10 \mathrm{wt} \%$. To arrive at suitable forms, published information on radioactive high level waste (HLW) immobilization technologies was reviewed; 72 uniquely named forms were identified. After pre-screening, candidate forms were further screened using multiattribute utility analysis to determine the most promising technologies for $\mathrm{Pu}$ immobilization. Promising immobilization familiesglass, ceramics, and metals-were then evaluated to identify inherent chemical, engineering, environmental, safety, and health problems and to seek solutions for them before making technical decisions as to the viability of using any of the families for long-term disposition of $\mathrm{Pu}$. We are also assessing modifications required to existing U.S., British, and French HLW immobilization approaches with respect to environmental, safety, and health implications, as well as costs and schedule. All data, analyses, and reports are being provided to the DOE/MD to support the Record of Decision that is anticipated in the fourth quarter of FY96.

\subsection{SPENT FUEL STANDARD}

To clarify the issue, the NAS (Ref. 1) coined the term "spent fuel standard" as follows: "Options for long-term disposition of plutonium should seek to meet a 'spent fuel standard' in which the plutonium is inaccessible for weapons use similar to the much larger and growing quantity of plutonium that exists in spent fuel from commercial power reactors."

The standard consists of four parts: radiological, physical, chemical, and nuclear properties. The first three directly influence requirements, regulations, and practices for applications of domestic and international safeguards and security; therefore, these properties must satisfy the standard. Plutonium isotopic compositions have only secondary effects and thus are not considered as a criterion in meeting the spent fuel standard. 


\section{SELECTION OF WASTE FORMS FOR IMMOBILIZING PLUTONIUM}

A literature search identified 72 waste forms (Ref. 2) by unique names (but only 45 unique forms) that have been considered for immobilizing radioactive wastes. Individual forms can be grouped into eight families that share common chemical and physical characteristics. These families are calcine, cementitious, ceramic, glass, glass-ceramic, metallic, multibarrier, and polymeric. Distinct waste forms are distinguished by unique physical and chemical properties. A screening process was implemented to select the best waste forms for the Pu disposition application. A more detailed discussion of the screening process is given elsewhere (Ref. 3), a summary of the process is given below.

\subsection{PRESCREENING PROCESS}

A two-stage approach (Fig. 2), based on decision analysis techniques, was adopted for screening. This allowed more rigorous selection techniques to be used as options became more closely matched. Stage 1 applied a small set of criteria to a large number of forms; this quickly removed forms that were clearly inappropriate for $\mathrm{Pu}$ immobilization. Stage 2 more closely evaluated remaining forms with the goal of selecting a small set $(\leq 3)$ of the best forms. Stage 2 involved a more formal comparison of waste form characteristics using multiattribute utility analysis techniques from decision analysis principles.

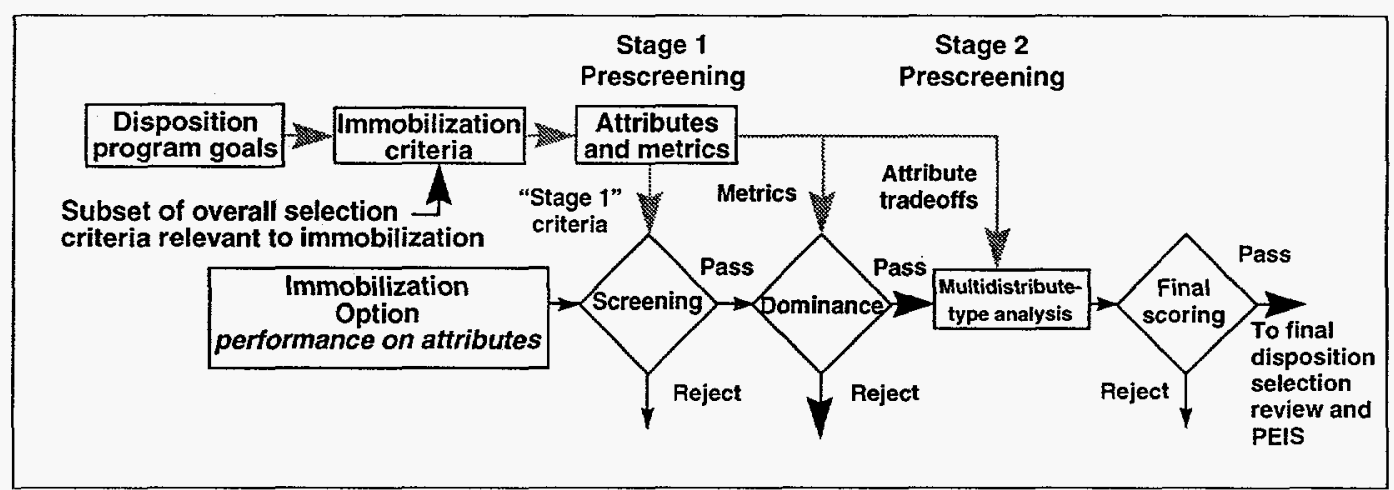

Figure 2. Pu immobilization prescreening process.

The results from individual and combined technical assessments and value and tradeoff assessments are shown in Table 1. "Utility" is the overall figure of merit for a form. 
Table 1. Ranking of forms according to weightings and utility curves.

$\begin{array}{lll}\text { Form } & \text { Utility } \\ \text { Borosilicate Glass } & 0.8949 \\ \text { Synroc } & 0.6592 \\ \text { Phosphate Glass } & 0.5516 \\ \text { Monazite } & 0.4879 \\ \text { Metallic Alloy } & 0.469 \\ \text { High Silica Glass } & 0.4449 \\ \text { FUETAP Concrete } & 0.4014 \\ \text { Hot-Pressed Concret } & 0.2457 \\ \text { Phos.-bnded Ceramic } & 0.1731 \\ \text { Silicon-Zirc Phosph } & 0.1704 \\ \text { Ceramics in Concret } & 0.1365 \\ \text { Iron-Enriched Basal } & 0.1335 \\ \text { Ceramic Pell. in Me } & 0.13 \\ \text { Supercalcine } & 0.07682 \\ \text { Glass-Ceramic Monol } & 0.02842 \\ \text { Cermet } & 0\end{array}$

\subsection{IMMOBILIZATION OPTIONS}

Seven immobilization options comprising three technologies are being evaluated in the PEIS process:

- Vitrification

- Internal radiation barrier

- New vitrification facilities

- Defense Waste Processing Facility (DWPF) adjunct melter

- External radiation barrier

- Glass Material Oxidation and Dissolution System (GMODS)

- Ceramics

- Internal radiation barrier

- External radiation barrier

- Electrometallurgical Treatment

\section{VITRIFICATION OF PLUTONIUM IN BOROSILICATE GLASS}

Criticality control is much easier in preparing crystalline ceramics than in preparing glass monoliths. Reference 3 discusses crystalline ceramics in more detail. In this paper, only borosilicate glass is discussed as the immobilization medium. 


\subsection{CONVENTIONAL VITRIFICATION TECHNOLOGY}

The technical basis for plutonium vitrification in borosilicate glass derives from nearly 40 years of international development and decades of commercial production of borosilicate glass to stabilize HLW. Borosilicate glass has gained international acceptance in the Western World as the waste form for HLW (Ref. 4). Preliminary work has shown that plutonium can be incorporated in borosilicate glass, providing an indication that plutonium-glass can be developed into a relatively safe, durable, accountable, and monitorable form (Refs. 5-8).

World-wide, various equipment and processes are in commercial use to produce borosilicate glass for an assortment of commercial applications, both with and without the incorporation of radioactive elements. These technologies could be adapted to produce plutonium-glass. Although differences exist among applications and the associated equipment-including feed compositions, melter designs, scale of equipment, and heating methods - the basic compositions and properties of the final glass products are similar.

The choice of a heating method depends on the particular application, the scale of the equipment, feed composition, final form requirements, and other considerations. Heating methods in common use include joule, radiant energy, induction, microwave, and plasma.

The most thoroughly demonstrated process for HLW vitrification is the one developed at Marcoule, France (Ref. 9), which (with minor alterations) is being used in the United Kingdom, France (LaHauge), and Japan. This two-step process first calcines an aqueous acidic waste. The resulting dry, calcined material is fed to an induction glass melter. In the United States, most HLW are alkaline, containing significant quantities of sodium and aluminum. The United States uses a singlestep vitrification process in which the waste is in the form of a liquid slurry and is fed directly to the melter. The Defense Waste Processing Facility (DWPF) at the Savannah River site (SRS) is scheduled to begin "hot" (with radioactivity) operation late this year. Other vitrification plants for HLW soon will be operating in Germany, the United States, and Japan. Vitrification plants for low-level waste (LLW) are even more commonplace.

Figure 4 is a block flow diagram for a generic process to vitrify plutonium in borosilicate glass. In this process, the gamma radiation field is assumed to be provided by the isotope ${ }^{137} \mathrm{Cs}$ in the form of ${ }^{137} \mathrm{CsCl}$ from the inventory presently stored at the Hanford Site (Ref. 10).

Although HLW vitrification is relatively well developed, $\mathrm{Pu}$ vitrification requires investigation of several issues before a production plant can be built. In the field of glass chemistry, we must determine the optimum glass composition to 


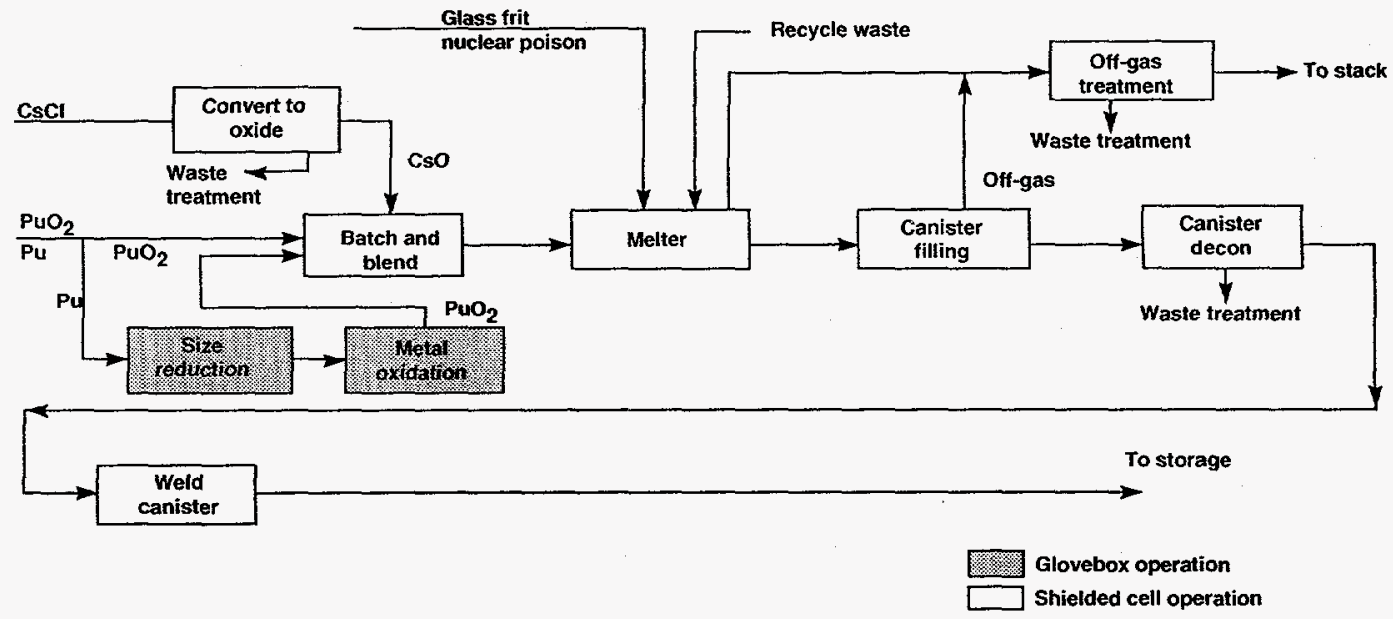

Figure 4. Vitrification block flow diagram.

yield a durable product with an acceptably low Pu leach rate. In addition, process and equipment development must be done for the various plant unit operations to reduce risk in deploying the production plant. Finally, but not least, the issues associated with criticality must be addressed for each step of the immobilization process, from preparing the input feed material to producing the final waste form.

\subsection{NUCLEAR CRITICALITY}

It is assumed that the facility will process about $25 \mathrm{~kg}$ of Pu per operation day. This amount of $\mathrm{Pu}$ represents more than 50 times the minimum critical mass for $\mathrm{Pu} /$ water systems and is greater than the maximum critical mass for dry, spherical, $\mathrm{PuO}_{2}$ systems. Therefore, criticality safety is clearly a major concern in designing vitrification processes.

\subsubsection{Process Criticality Safety}

A nuclear criticality accident is the result of inadvertently producing conditions that allow a self-sustaining or divergent neutron chain reaction. These conditions are present when the effective neutron multiplication factor $\left(k_{\text {eff }}\right)$ for a system of fissionable material is $\geq 1$. The $k_{\text {eff }}$ for any system of fissionable material is a complex function that depends on 
- The mass and distribution of all fissionable materials within the system.

- The mass, distribution, and nuclear properties of all other materials associated with the system.

Operations with fissionable materials always present a risk of nuclear criticality accidents. Nuclear criticality safety is achieved by controlling one or more of the parameters that affect $k_{\text {eff }}$ within subcritical limits. These controls may be achieved through

- Geometry restraints such as limiting the diameter of tanks that contain fissionable materials within the subcritical limit.

- Use of instrumentation, such as devices to limit the concentration of fissionable material in a process.

- Administrative controls, such as procedures to limit the inventory of fissionable material in a process.

- Use of nuclear poisons to reduce $k_{\text {eff }}$.

DOE Order 5480.24 requires application of the double contingency principle:

"Process designs shall incorporate sufficient factors of safety to require at least two unlikely, independent, and concurrent changes in the process conditions before a criticality accident is possible. Protection shall be provided by either (a) the control of two independent process parameters (which is the preferred approach, if practical) or (b) a system of multiple (at least two) controls on a single parameter. In all cases, no single failure shall result in the potential for a critical accident."

DOE Order 5480.24 also ranks, in order of preference, the different types of control that may be used to ensure criticality safety. Process designs are to rely on passive geometry controls whenever possible. When these are not possible, the order of preference is for other passive engineered controls, active engineered controls, and finally, administrative controls.

ANSI/ANS-8.1 allows the use of neutron absorbers for criticality control. Extreme care is required with solutions of absorbers because of the difficulty of exercising this type of control.

ANSI/ANS-8.1 requires that subcritical limits shall be established with adequate allowances for uncertainties. Methods of calculation used to determine $k_{\text {eff }}$ for a system or used to establish subcritical limits shall be validated. The bias in the results shall be determined. The calculation shall incorporate sufficient margin to ensure subcriticality. The margin of subcriticality shall include allowances for the uncertainty in the bias. 
No criticality analysis of the vitrification process has yet been done. The criticality issues for each stage of the immobilization process are discussed below. These issues are assessed based on engineering judgment and extrapolation from similar processes. These assessments produce criticality safety assumptions used to size the facility. They also indicate that it will be possible to produce facility, process, materials-handling, and waste-form designs that satisfy all applicable criticality safety requirements. However, all of these criticality safety assumptions and assessments require confirmation that can be provided only by a detailed criticality safety evaluation.

\subsubsection{Vitrification Specific Criticality Issues}

Nuclear criticality avoidance is ensured by three mechanisms: process design, process instrumentation, and nuclear safety systems. Each of these is examined below.

Process Design. The locations of buildup of FMs in the processing system depend upon the process chemistry; thus, the first level of nuclear criticality safety is a detailed understanding of the fissile material process chemistry. A number of processing decisions have not yet been made, and a number of critical parameters have not been determined.

Experiments to date on the solubility of plutonium in glass primarily have focused on the low concentrations of plutonium in the various waste streams instead of the solubility of high-concentration feed stocks. As such, experiments have focused on whether these low concentrations are soluble in the various glass formulations-very little experimentation has therefore been done on plutonium concentrations in glass above about 2 to $3 \mathrm{wt} \% \mathrm{Pu}$. Experimental data, which have been done above the 2- to 3-wt\% concentration level, are sparse and conflicting even when the experiments were done under nearly the same conditions. As a result of the conflicting data, an experimental program is under way to determine the solubility of various Pu feed stocks under varying process conditions and cycle times. These experiments, however, will not be done in time to support the PEIS.

Because of this, a two-step approach has been taken to all vitrification flowsheets. The first step is the conversion of $\mathrm{PuO}_{2}$ to $\mathrm{Pu}$-borosilicate glass in small batches. To satisfy the double contingency principle, a batch process based on a bottom-draining, geometrically favorable melter such as the Bushing Melter (wrapped with a neutron-loaded insulation, if necessary) and the ever-safe, waterreflected $\mathrm{PuO}_{2}$ sphere mass limits are being considered for the PEIS flowsheets. For weapons-grade plutonium (i.e., about $6 \%{ }^{240} \mathrm{Pu}$ ), the ever-safe $\mathrm{PuO}_{2}$ sphere mass is $4.53 \mathrm{~kg}$. Preliminary calculations suggest that, until the plutonium is 
dissolved into the borosilicate glass, the safe mass in a melter may be as high as $27 \mathrm{~kg}$; provided the water content is held to less than $3 \%$ of the plutonium content. More definitive calculations will be performed as the design firms up; at the present time, for the PEIS, it is sufficient to know that the batch size will be $<27 \mathrm{~kg}$.

Once the $\mathrm{Pu}$ has dissolved into the borosilicate glass to give a homogeneous melt, then the $k_{\text {eff }}$ drops to a very low value $(<<0.1)$. Therefore a larger melter containing much more $\mathrm{Pu}$ can be used for the second stage of vitrification. Glass frit added to the second stage also will have an additional dose of neutron poison dissolved in it beyond just the boron inherent in the glass-gadolinium or other rare earth, hafnium, and other neutron poisons have been suggested.

Once the kinetics of dissolution and the solubility of plutonium in the specific glass formulation have been determined, and the melter design decided upon, then full-scale criticality calculation will be done for the specific process chosen. Until that time, the conservative approach will be taken for the PEIS.

Process Instrumentation. At the level of analysis required for the PEIS, actual instrumentation need not be specified-just that the type of instrumentation required is available. Avoidance of nuclear criticality also will be guarded against by on-line process control systems that measure the concentrations and quantities of FMs in the various parts of the plant process. This capability is required for process-control purposes independent of nuclear criticality considerations, but the process-control system also has the capability to confirm that concentrations of FMs are not building up within the system. Product requirements necessitate a uniform glass-product composition, starting with highly heterogeneous feed stocks. This requires multiple measurement and control systems to ensure production of a homogenous glass product.

\subsubsection{Nuclear Safety Systems}

The nuclear safety systems are those items required to ensure criticality control. Therefore, the system is a combination of facility and equipment design, instrumentation, and process control. To the extent possible, engineered design features will be designed into the system to prevent criticality. Only where absolutely necessary will administrative control be used.

\subsubsection{Repository Criticality Safety}

Criticality control can be maintained in the repository by using a combination of fissile concentration, immobilization matrix, neutron poisons, overpacks, backfills, etc. The three items within the control of the Immobilization Task are fissile concentration, the immobilization matrix, and neutron poisons. 
Fissile Concentration. The range of plutonium concentrations being examined for immobilization is about 0.4 to $10 \mathrm{wt} \%$. Below that range, the cost is considered to be prohibitive. Above that range, the immobilized form is considered to be too attractive as a target for a potential proliferant. Within this range, however, there is some flexibility for criticality considerations. For the purposes of the PEIS, the external radiation cases have been arbitrarily set at $10 \mathrm{wt} \% \mathrm{Pu}$ and the internal radiation cases at $5 \mathrm{wt} \% \mathrm{Pu}$. The final average concentrations in both cases is $5 \mathrm{wt} \%$. After the PEIS is complete, more detailed calculations will be performed to verify or change the original assumptions on plutonium concentration.

Immobilization Matrix. For criticality safety to be maintained over time in the repository, the glass formulation must optimized so that it will

- Not undergo phase devitrification;

- Minimize the formation of crystalline phases that have a negative effect on the chemical durability of the final form;

- Minimize inhomogeneity, amorphous phase separation, devitrification, etc.;

- Have a reasonable high glass transition temperature;

- Have low leach rates of both the FMs and the neutron poison; and

- Have similar leach rates for plutonium and the neutron poison.

An $R \& D$ program is under way to determine the glass formulation that will be acceptable from a processing perspective as well as durable enough to prevent migration and separation of the plutonium and the neutron poison into the host rock strata.

\section{CONCLUSIONS}

Three primary immobilization forms have been identified for possible use in the Fissile Material Disposition Program. These are borosilicate glass, crystalline ceramics, and metals. Borosilicate glass has been the subject of this paper. The primary safety problem for any of the immobilization forms is criticality control during form fabrication. Through the PEIS process, initial assessments indicate that the primary method of criticality control should, conservatively, be mass and geometry control. As the design for the process continues, more detailed calculational methods will be employed to determine if it is reasonable to relax the mass control somewhat. Mass and geometry control have dictated a two-step vitrification process. If the mass controls can be relaxed sufficiently, the two-step process will be rejected in favor of a cheaper one-step process. 


\section{ACKNOWLEDGMENT}

This work was performed under the auspices of the U.S. Department of Energy by the Lawrence Livermore National Laboratory under Contract No. W-7405-Eng-48.

\section{REFERENCES}

1. National Academy of Sciences, Management and Disposition of Excess Weapons Plutonium (National Academy Press, Washington, DC, 1994).

2. Screening of Alternate Immobilization Candidates for SFM Disposition, Predecisional Draft, Lawrence Livermore National Laboratory, Nov. 1995.

3. L. W. Gray et al., "Immobilization as a Route to Surplus Fissile Materials Disposition," accepted for presentation at ASME's Fifth International Conference on Radioactive Waste Management and Environmental Remediation, September 3-7, 1995, Berlin, Germany, and to be published in the Proceedings (1995)

4. W. Lutze and R. C. Ewing, Eds., Radioactive Waste Forms for the Future (North-Holland, Amsterdam, 1988).

5. G. G. Wicks, J. M. McKibben, and M. J. Plodinec, "Vitrification of Excess Plutonium," presented at Waste Management '95, Feb. 26-Mar. 1, 1995, Tucson, AZ, and accepted for publication in the Proceedings (1995).

6. J. M. McKibben and G. G. Wicks, "Vitrification of Excess Plutonium," presented at the International Policy Forum: Management and Disposition of Nuclear Weapons Materials, Leesburg, VA (1994).

7. J. M. McKibben, R. W. Benjamin, D. F. Bickfor, L. P. Fernandez, W. N. Jackson, W. R. McDonnell, E. N. Moore, P. B. Parks, M. J. Plodinec, W. M. Rajczak, S. K. Skiles, and G. G. Wicks, Vitrification of Excess Plutonium (U), WSRC-RP-93-755, Predecisional Draft, Westinghouse Savannah River Company (1993).

8. G. G. Wicks, "Nuclear Waste Glasses," Treatises on Materials Science and Technology, Glass IV, M. Tomozawa and R. H. Doremus, Eds., Vol. 26 (Academic Press, Inc., New York, 1985), pp. 57-188.

9. C. G. Sombret, "The Vitrification of High-Level Radioactive Wastes in France," Nucl. Energy 24(2), 85 (1985).

10. R. R. Jackson, "Hanford Waste Encapsulation: Strontium and Cesium," Nucl. Technol. 32, 10 (1977). 